\title{
Dose Assessment for Some Industrial Gamma Sources with an Application to a Radiation Accident
}

\author{
Eman Massoud \\ Radiation Protection Department, Nuclear and Radiological Regulatory Authority, Cairo, Egypt \\ Email: emanmassoud@yahoo.com
}

Received October 5, 2013; revised November 23, 2013; accepted December 3, 2013

Copyright (C) 2014 Eman Massoud. This is an open access article distributed under the Creative Commons Attribution License, which permits unrestricted use, distribution, and reproduction in any medium, provided the original work is properly cited. In accordance of the Creative Commons Attribution License all Copyrights (C) 2014 are reserved for SCIRP and the owner of the intellectual property Eman Massoud. All Copyright (c) 2014 are guarded by law and by SCIRP as a guardian.

\section{ABSTRACT}

Accidents involving industrial radiography are the most frequent cause of severe or fatal overexposure to workers and the public. On May 5, 2000, a radiation accident happened at a construction site in a gamma radiography practice at the village of Meet Halfa-Egypt. The accident was a severe overdose of non-radiation workers due to external exposure of Ir-192. This paper provides a methodology for calculating doses and dose rates from the most commonly used industrial $\gamma$-sources: ${ }^{192} \mathrm{Ir},{ }^{60} \mathrm{Co},{ }^{134} \mathrm{Cs},{ }^{137} \mathrm{Cs}$ and ${ }^{131} \mathrm{I}$. For this purpose, MCNP computer code based on Monte Carlo technique is used. The applied method helps firstly in studying and analyzing the doses from the above mentioned sources. Secondly, it provides a lead container design in a trial to reduce the dose rate within the permissible. Computer models were used to simulate the ${ }^{192}$ Ir Meet Halfa accident. To verify these models, the calculated doses were compared with a well-known empirical formula to convert source activity into dose rate and then the models were applied at different distances to analyze the factors that affect the deposited dose in the human body to find out the dose received by the victims.

\section{KEYWORDS}

\section{Radiation Accidents; Sources Used in Industry; Dose Assessment}

\section{Introduction}

The use of radioactive materials continues to offer a wide range of benefits throughout the world in medicine, research and industry. Precautions are, however necessary in order to protect people from the detrimental effects of the radiations. Where the amount of radioactive material is substantial with sources used in radiography or industrial radiography, extreme care is necessary to prevent accidents that may have severe consequences for the individuals affected. Although other techniques of NDT (Non-Destructive Tests) methods have also been developed and widely implemented, the unique details of data obtained by radiography and the fingerprint as a film, have caused radiography to be more appreciated and preferred for the volumetric inspection of products [1]. Simplicity in application and accepted results of radiography using radiation sources are the major reason to consider these sources most predominant in Egypt. Typical $\gamma$-ray sources which are commonly used in field applications are ${ }^{192} \mathrm{Ir},{ }^{60} \mathrm{Co},{ }^{134} \mathrm{Cs},{ }^{137} \mathrm{Cs},{ }^{131} \mathrm{I}$ and ${ }^{99} \mathrm{Tc}$ [2-4]. As shown in Figure 1, about one third of radiation accidents occur in industry, roughly each eighth of them in connection with the medical application of sources of ionizing radiation, while close to one third of them have nuclear origin. Radiation accidents are the rarest in the transport and waste management or military application of radioactive materials or devices. About one half of radiation accidents are caused by ${ }^{192} \mathrm{Ir}$ and one quarter of them by ${ }^{60} \mathrm{Co}$ while the remaining $23 \%$ are due to ${ }^{137} \mathrm{Cs}$, radium, uranium, transuranic elements or unknown isotopes [4]. A radiation accident is different from accidents in other fields as the effects of radiation are not immediately felt. Because of this insidious nature, a radiation accident can lead to very serious consequences. The likelihood of occurrence of an accident in industrial radiography is fairly high [5], because majority of the radiography work is carried out in public domain, such as con- 


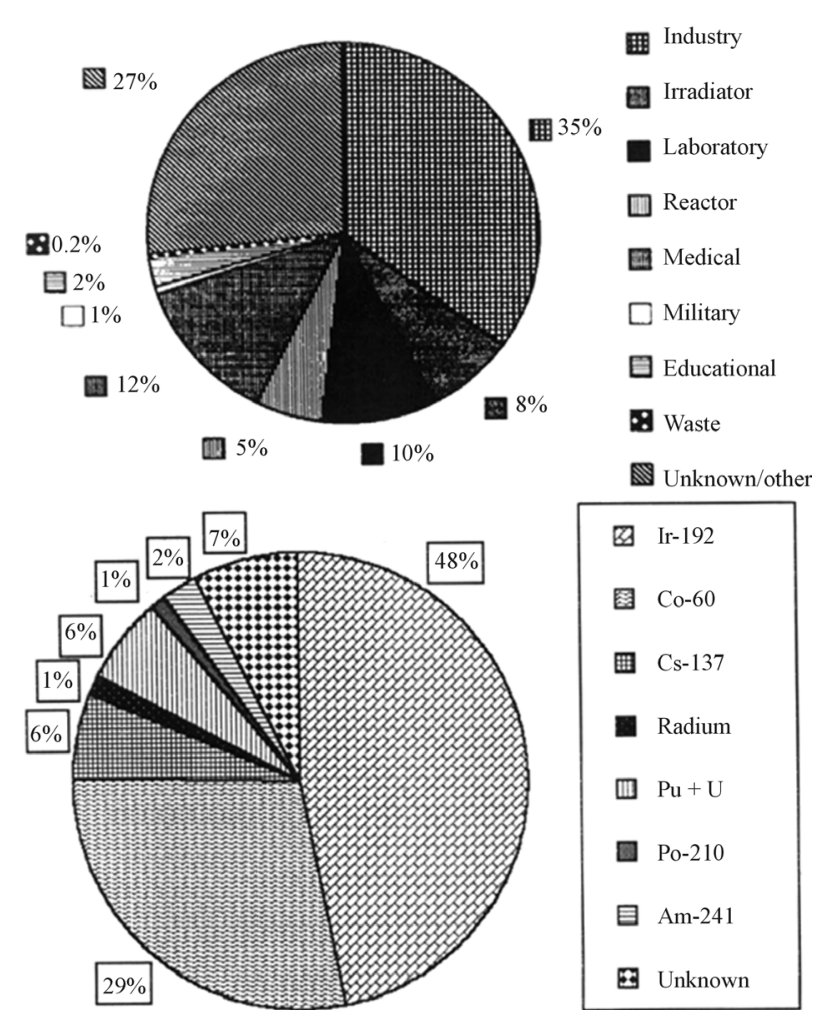

Figure 1. Distribution of radiation accidents according to the type of facility and the radioisotopes involved, from 1945 to 2000 [3].

struction sites, workshop areas and inaccessible locations. The source activities used in industrial radiography are quiet high, hence in the event of an accident; there is the possibility of very high doses, even up to lethal doses in certain cases. Accidents and consequent radiation exposure/injury during use happen mainly because of the following reasons:

- handling of sources by untrained persons,

- use of defective equipment and/or its failure,

- failure to use radiation meter.

MCNP4B computer code [6,7] based on Monte Carlo techniques was used to design a computer model which studies and analyzes the doses from $\gamma$-sources and design a lead container which reduces the dose rate from these sources to less than $1 \mu \mathrm{Sv} / \mathrm{h}$. Also, exposure from ${ }^{192} \mathrm{Ir}$ source is studied to simulate Meet Halfa accident. This is to analyze and simulate the dose received by the infected persons. Several scenarios are assumed and the dose rate from each scenario is compared with the documented accident dose.

\section{Industrial Radiography Sources \& Devices}

Industrial radiography sources and devices are generally small in terms of physical size, although the devices are usually heavy due to the shielding contained in them. The sources themselves are very small, less than $1 \mathrm{~cm}$ in diameter, and only a few $\mathrm{cm}$ long, and are attached to specially designed cables for their proper operation.

The use of radiography sources and devices are very common, and their probability may make them susceptible to theft or loss. The small size of the source allows for unauthorized removal by an individual, and such a source may be placed into a pocket of a garment.

Industrial radiography may also be performed in fixed installations, either using the same small portable devices, or using larger machines that may appear to be similar to teletherapy units [8]. Iridium-192 is ideal for radiography but other radionuclides can be used depending on the characteristics of the object material [9].

\section{Meet Halfa Accident}

On May 5, 2000, welds on pipes located near Meet Halfa village 15 km from Cairo, where pipes were radio- 
graphed with $31.5 \mathrm{Ci}^{192} \mathrm{Ir} \gamma$-ray source. At the end of the shift, the iridium source became detached from its drive cable, may be due to failure of the lock on radiography container. This resulted in the source falling on the ground. A resident from Meet Halfa village found the source and take it to his house where he lives with his family. In the days that followed the source was handled by the man and his family members. They were subjected to direct gamma radiation exposure of different intensities from different distances. The source was packed up by the national authorities at June 26, 2000. The sequence of events developed over a period of 52 days from the time the source was found, on May $5^{\text {th }}$ until the day of its retrieval from the house by the authorities on June $26^{\text {th }}$, a death of a 9-year-old child at June $5^{\text {th }}$ and his father death at June $16^{\text {th }}$. The reminder of the family has received a considerable dose from the source [10].

\section{MCNP Computer Model}

MCNP4B computer code is a neutron, photon and electron transport code [7]. The code was used to simulate the history of the three particles based on Monte Carlo techniques. In this study the code is used to model the transport of gamma rays from the different radioactive sources ${ }^{192} \mathrm{Ir},{ }^{60} \mathrm{Co},{ }^{134} \mathrm{Cs},{ }^{137} \mathrm{Cs},{ }^{131} \mathrm{I}$, and ${ }^{99} \mathrm{Tc}$ with activity 20 Ci. The angular distributions of the gamma sources are isotropic in $4 \pi$. The code model is used to determine the gamma flux and its corresponding equivalent dose rate in $\mu \mathrm{Sv} / \mathrm{h}$. The built in MCNP flux to dose correction factor ANSI is also applied. The point detector techniques of MCNP code are used in the calculation of the dose rate at large distance to optimize Monte Carlo precision and results.

\section{Development of Scenarios for Exposure Estimates}

In Meet halfa accident simulation:

a) Model for a human body was designed.

b) A typical composition for the human body were used [11].

c) The energy depositions of gamma rays over all the body were calculated using the MCNP code.

d) The integral deposited dose was calculated with time at different distances from the source.

e) The factors that affect the calculated dose rate in $\mu \mathrm{Sv} / \mathrm{h}$ and deposited energies in Gy were analyzed and studied through different accident scenarios to approximate the calculated MCNP dose with the actual dose rate received through the accident. The source activity on May 5, 2000 was $31.5 \mathrm{Ci}$, the day the source was found and came into possession of the family. On 26 June 2000, the day the source was retrieved, its activity was $19.35 \mathrm{Ci}$, applying the decay law to ${ }^{192}$ Ir with half life time 74 days, as family members were in possession of the source from May 5 to June 10 where they admitted to the hospital. They received an accumulated dose as mentioned in Table 1 [10].

The factors considered that affect the dose received by the people are the distance from the gamma ray source (D) and the time of exposure to the source (h). In this study, three scenarios are applied. They should fulfill all the expected accidents from the radio graphical sources mentioned above. Recognizing that in some cases it may be beneficial to combine two or more scenarios. In addition to typical accident situation, these scenarios included other situations that may be applicable to malevolent acts. In this work, a methodology is developed for dose assessment based on an empirical formula [12]. It is used to calculate dose rate in $\mathrm{mSv} / \mathrm{h}$ from different $\gamma$-sources, and given by the relation:

Table 1. Radiation dose to exposed family [10].

\begin{tabular}{cc}
\hline Persons & Dose (Gy) \\
\hline Father & 7.5 to 8 (died) \\
Younger son & 5 to 6 (died) \\
Elder son & 3.5 to 4 \\
Sister & 3.5 to 4 \\
Wife & 3.5 to 4 \\
Younger daughter & 3.5 to 4 \\
Elder daughter & 3.5 to 4 \\
\hline
\end{tabular}


Dose rate $(\mathrm{mSv} / \mathrm{h})=$ Gamma factor $\times$ Source Activity $/(\text { distance })^{2}$ Where:

The dose rate: is the gamma dose rate in $\mathrm{mSv} / \mathrm{h}$.

Gamma factor: is the correlation factor depends on type of isotope (given at Table 2).

Source Activity: Activity of radioactive isotopes in GBq.

Distance: is the distance from the source in $\mathrm{m}$.

\section{Results and Discussions}

The following results represent the dose rate calculation by MCNP code and empirical formula for ${ }^{192} \mathrm{Ir},{ }^{60} \mathrm{Co}$, ${ }^{134} \mathrm{Cs},{ }^{137} \mathrm{Cs}$, ${ }^{131}$ I and ${ }^{99} \mathrm{Tc}$ consequently.

Figure 2 illustrates comparison between the present MCNP model and empirical formula. They are used for dose rate calculation of ${ }^{192} \mathrm{Ir}$ source with activity $20 \mathrm{Ci}$. The results show good agreement between the two methods applied. The percentage of error at $60 \mathrm{~m}$ from the source is $8 \%$. At distance $~ 50 \mathrm{~m}$, the percentage of error is further reduced to $2 \%$. The dose rate at $50 \mathrm{~cm}$ from the source is $4.0 \times 10^{5} \mu \mathrm{Sv} / \mathrm{h}$ and at $60 \mathrm{~m}$ is $26 \mu \mathrm{Sv} / \mathrm{h}$.

Figure 3 shows the dose rate calculated using the present MCNP model and empirical formula for the $20 \mathrm{Ci}$ ${ }^{60} \mathrm{Co}$ source. The error for the two methods doesn't exceed $5 \%$ at $60 \mathrm{~m}$. The dose rate at $0.5 \mathrm{~m}$ from the source is $1.1 \times 10^{6} \mu \mathrm{Sv} / \mathrm{h}$ and at $60 \mathrm{~m}$ is $72 \mu \mathrm{Sv} / \mathrm{h}$. Also, the results indicate that the dose rate from ${ }^{60} \mathrm{Co}$ is higher than ${ }^{192}$ Ir at the same intensity and for both short and long distances from the source.

Figure 4 illustrates the dose rate of Cs137 $\gamma$-source with activity $20 \mathrm{Ci}$. The results compare between the present MCNP model and emperical formula. The difference error is $9 \%$ at distance $60 \mathrm{~m}$ from the source. The results show that the maximum dose rate is $2.94 \mathrm{E}+5 \mu \mathrm{Sv} / \mathrm{h}$ at $0.5 \mathrm{~m}$ from the source and at larger distance $\sim 60 \mathrm{~m}$; the calculated dose rate is $1.49 \mathrm{E}+1 \mu \mathrm{Sv} / \mathrm{h}$.

Figure 5 illustrates the dose rate of Tc-99 source of activity $20 \mathrm{Ci}$. The difference error is $12 \%$ at $60 \mathrm{~m}$ from the source. The maximum dose rate is $7.89 \mathrm{E}+4 \mu \mathrm{Sv} / \mathrm{h}$ at $0.5 \mathrm{~m}$ from the source, and $3.41 \mu \mathrm{Sv} / \mathrm{h}$ at $60 \mathrm{~m}$ from the source.

Figure 6 represents the calculated dose rate for $\mathrm{I}^{131}$ source of activity $20 \mathrm{Ci}$. The max dose rate is $2.29 \mathrm{E}+5$ $\mu \mathrm{Sv} / \mathrm{h}$ at $0.5 \mathrm{~m}$ and the min dose rate is $1.08 \mathrm{E}+1 \mu \mathrm{Sv} / \mathrm{h}$ at $60 \mathrm{~m}$ from the source.

Table 2. Gamma factor for different radioactive isotopes [12].

\begin{tabular}{cc}
\hline Type of source & Gamma factor \\
\hline Ir-192 & 0.13 \\
Cobalt-60 & 0.351 \\
Caesium-137 & 0.081 \\
Iodine-131 & 0.06 \\
Technetium-99m & 0.022 \\
\hline
\end{tabular}

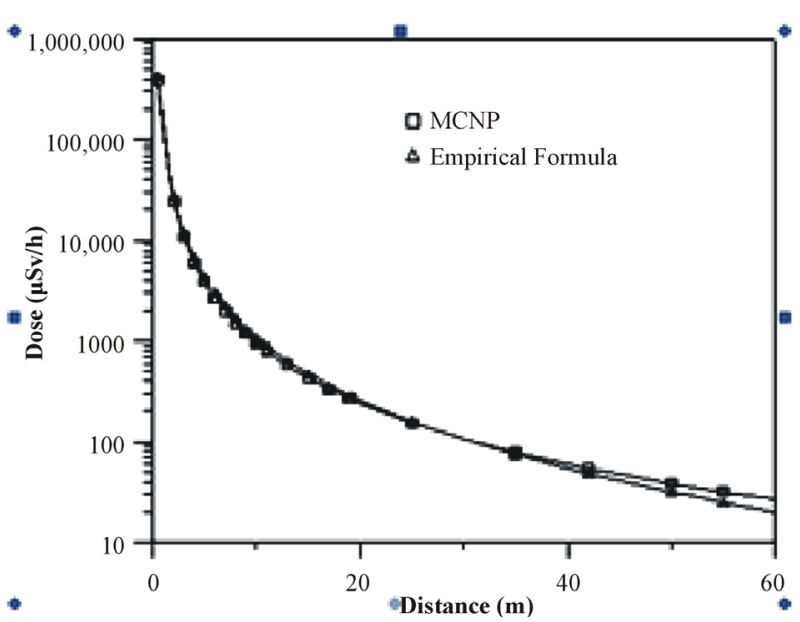

Figure 2. Dose rate $(\mu \mathrm{Sv} / \mathrm{h})$ versus distance $(\mathrm{m})$ from ${ }^{192} \mathrm{Ir}$ source $20 \mathrm{Ci}$ in air. 


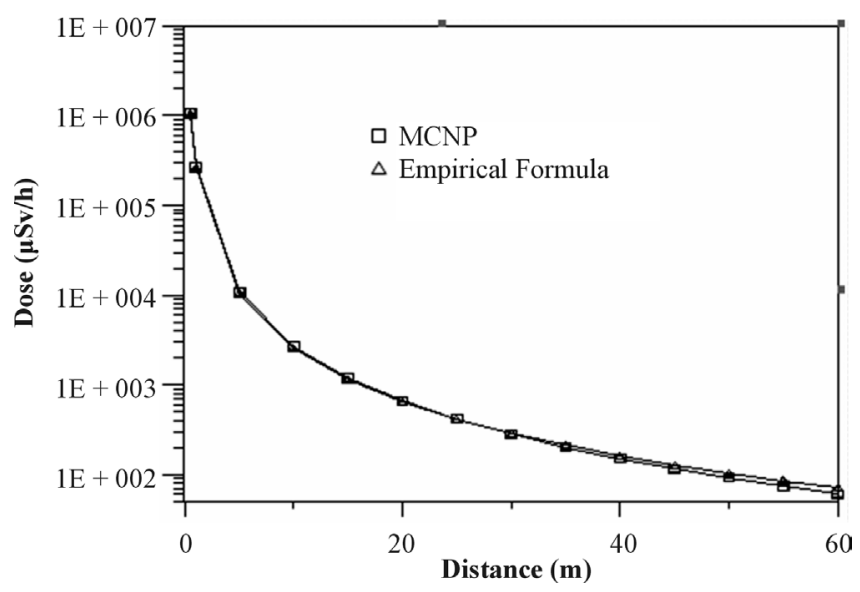

Figure 3. Dose rate calculations ( $\mu \mathrm{Sv} / \mathrm{h})$ versus distance in $(\mathrm{m})$ from ${ }^{60} \mathrm{Co} \gamma$ source with $20 \mathrm{Ci}$ in air.

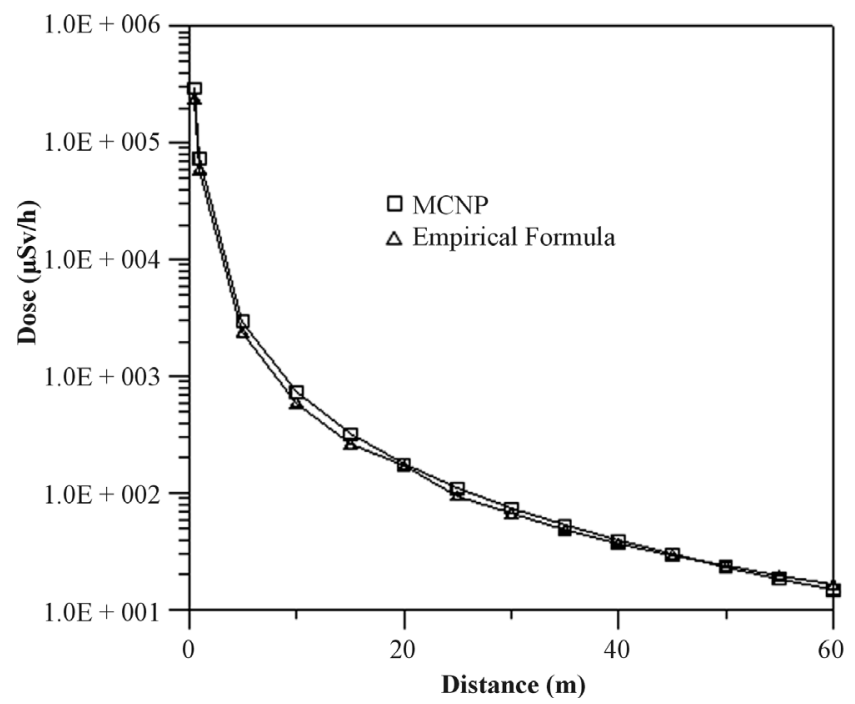

Figure 4. Dose rate calculations $(\mu \mathrm{Sv} / \mathrm{h})$ versus distance $(\mathrm{m})$ from ${ }^{137} \mathrm{Cs} \gamma$ source with $20 \mathrm{Ci}$ in air.

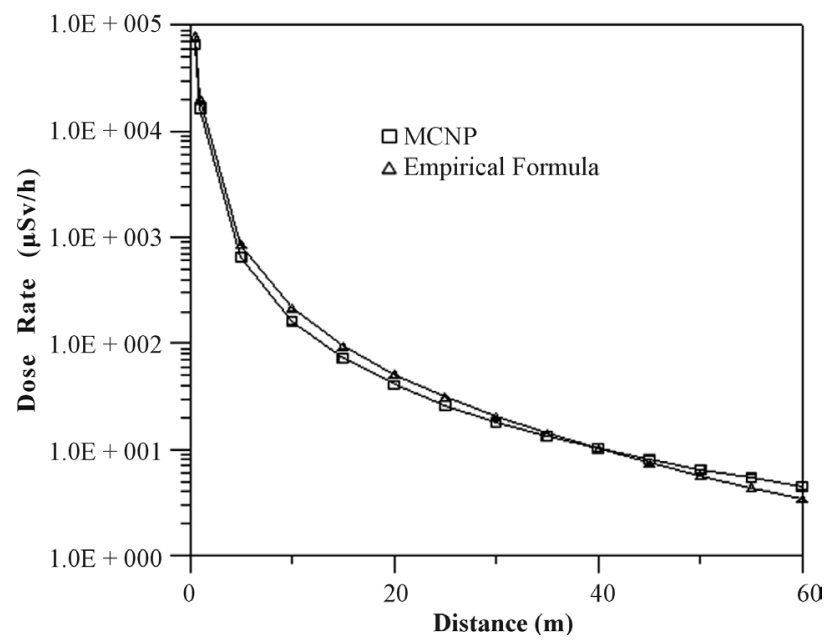

Figure 5. Dose rate calculation in $\mu \mathrm{Sv} / \mathrm{h}$ versus distance in $\mathrm{m}$ from ${ }^{99} \mathrm{Tc} \gamma$ source with $20 \mathrm{Ci}$ in air.

For the previous studied sources: ${ }^{192} \mathrm{Ir},{ }^{60} \mathrm{Co},{ }^{137} \mathrm{Cs},{ }^{99} \mathrm{Tc},{ }^{134} \mathrm{Cs}$, and ${ }^{131} \mathrm{I}$ a cylindrical lead container was designed. The calculated container's thickness is varied according to the source under consideration. The dose rate 
outside the container is reduced to the allowable levels i.e. $<1 \mu \mathrm{Sv} / \mathrm{h}$. Table 3 illustrates the calculated thickness of the container.

The deposited dose rate $(\mathrm{Gy} / \mathrm{h})$ is calculated for MCNP human body model due to exposure to ${ }^{192} \mathrm{Ir}$ gamma source with activity 31.5 Ci at May 5, 2000 and the source activity decrease up to $19.35 \mathrm{Ci}$ at June 26, 2000. The dose rate is calculated every day depending on the source activity at that day. The dose rate is integrated over all exposure time to obtain the integral dose received by all the human body. The parameters that affect the received dose are analyzed. The received dose depends on both the distance from source to the body and the exposure time to the gamma source.

Figure 7 illustrates different scenarios that the human body receives the integrated doses. The distance from the human body model to the source are varied from $2 \mathrm{~m}, 3 \mathrm{~m}$ and $5 \mathrm{~m}$ and the integrated dose are calculated for each bath. The father received receives dose between 7 - $8 \mathrm{~Gy}$, this can be explained through scenario (A) exposure from distance $2 \mathrm{~m}$. The father receives $8 \mathrm{~Gy}$ after full 24 days of exposure which indicates that he stayed two thirds (2/3) of his time only from 5 May to 10 June beside to the source. The reminder of the family can be explained through scenarios A and B. Scenario C is excluded because it does not agree with the dose received at Table 1.

Figure 8 illustrates the detailed three dimensional dose map (Gy) with exposure time (days) and distance (m), the figure is rotated 225 degree.

- The main victim who received 7 - 8 Gy was at $2 \mathrm{~m}$ from the source.

The main victim has received 7 - 8 Gy after 24 days of exposure. It indicates that he has stayed from $5^{\text {th }}$ May to $10^{\text {th }}$ June near the source (i.e. $2 / 3$ the entire period).

- Dose calculated for the remainder of the family is in coincidence with that found by this model in case of 2 and 3 meters.

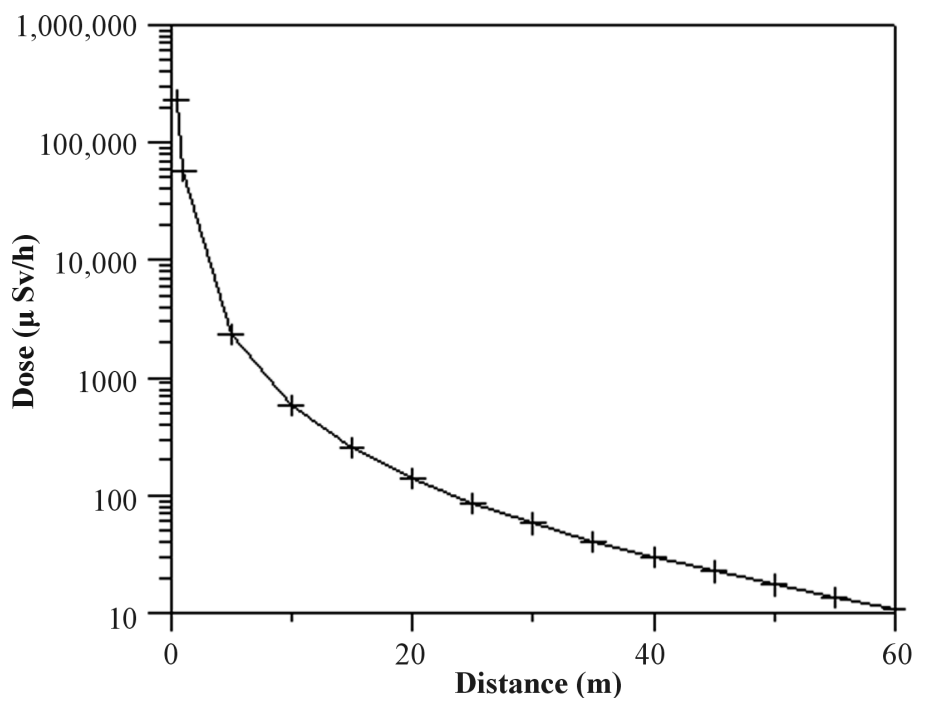

Figure 6. Dose rate calculation in $\mu \mathrm{Sv} / \mathrm{h}$ versus distance in $\mathrm{m}$ from ${ }^{131} \mathrm{I} \gamma$ source with $20 \mathrm{Ci}$ in air.

Table 3. Container thickness and equivalent dose rate $(\mu \mathrm{Sv} / \mathrm{h})$.

\begin{tabular}{ccc}
\hline Type of source & Container thickness $(\mathrm{cm})$ & Dose $(\mu \mathrm{Sv} / \mathrm{h})$ \\
\hline${ }^{192} \mathrm{Ir}$ & $10 \mathrm{~cm}$ & 0.33496 \\
${ }^{60} \mathrm{Co}$ & $22.5 \mathrm{~cm}$ & 1.47 \\
${ }^{134} \mathrm{Cs}$ & $18 \mathrm{~cm}$ & 0.5156 \\
${ }^{137} \mathrm{Cs}$ & $12 \mathrm{~cm}$ & 0.459 \\
${ }^{131} \mathrm{I}$ & $10 \mathrm{~cm}$ & 0.509 \\
${ }^{99} \mathrm{Tc}$ & $<1.0 \mathrm{~cm}$ & 0.1 \\
\hline
\end{tabular}




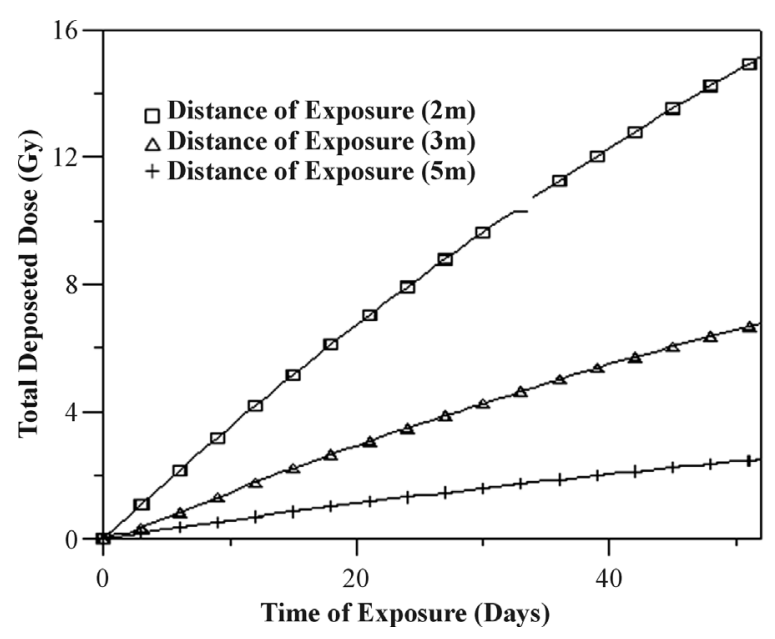

Figure 7. Total deposited dose (Gy) versus time of exposure (Day) for several distances from ${ }^{192}$ Ir source.

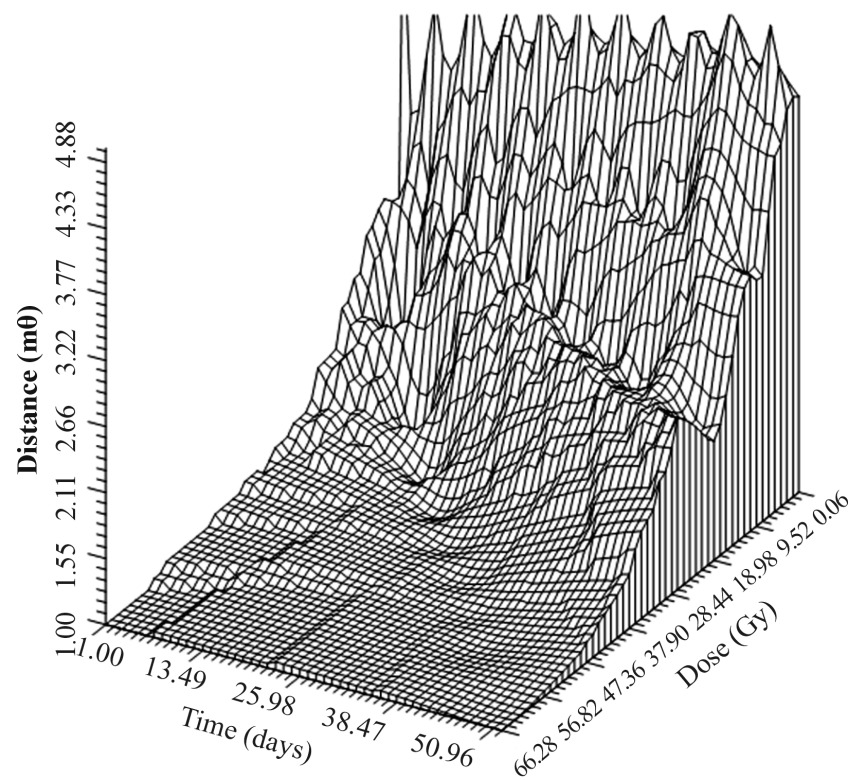

Figure 8. Three dimensional dose map for meet Halfa accident.

\section{Conclusions}

It is hoped that this work provides an approach to the radiological protection of both workers and members of the general public, scenarios, conditions of exposure and model parameters are selected which may lead to higher external or internal doses. In fact, the way in which critical groups of people is selected, according to their working or living conditions are subject to higher external exposure to $\gamma$-sources used in industry in case of accident. Further calculation of the ${ }^{192}$ Ir source used in radiography and based on exposure scenario, a group of general public is observed. Taking into account the exposure conditions at Meet Halfa accident, the deposited dose rate in Gy/h is calculated using MCNP model for human body. Also, the dose rate is calculated for each day the family was exposed (between May $5^{\text {th }}$ and June $26^{\text {th }}$ ) where the recorded activity was $31.5 \mathrm{Ci}$ and 19.35 Ci consequently. Moreover, the dose rate is integrated overall exposure time to obtain the integral dose received by the entire human body. The parameters that affect the received dose are analyzed, taking into consideration the radiation protection... time, distance

- Computer models were designed to determine the dose rate from six gamma sources, ${ }^{192} \mathrm{Ir},{ }^{60} \mathrm{Co},{ }^{134} \mathrm{Cs},{ }^{137} \mathrm{Cs}$, ${ }^{131} \mathrm{I}$ and ${ }^{99} \mathrm{Tc}$, which are frequently used in industry, medicine and researches.

- The thickness of lead container shield is designed which reduces the level of gamma rays dose rate outside the container to approximately $1 \mu \mathrm{Sv} / \mathrm{h}$, due to sources of activity $20 \mathrm{Ci}$. 
- MCNP computer code packages are used to simulate Meet Halfa accident, the accumulated deposited doses are determined for the infected persons. Different scenarios are assumed to obtain the dose map.

- The models of gamma sources can be extended to simulate the devices and instruments of these sources and calculate the dose rate in the case of normal and abnormal operations.

In developing the methodology presented in this work, the following conceptual restrictions were assumed:

- Only accidents of humans associated with industrial radiography are considered.

- Even though the scenarios and the dosimetric models are generic, parameter values are given and calculations are performed for ${ }^{192} \mathrm{Ir},{ }^{60} \mathrm{Co},{ }^{134} \mathrm{Cs},{ }^{137} \mathrm{Cs},{ }^{131} \mathrm{I}$ and ${ }^{99} \mathrm{Tc}$ only. Wherever necessary, the list of sources could be extended.

\section{REFERENCES}

[1] A. Kumar, M. J. Subramanya, C. P. Raghavendran, B. K. S. Murthy, R. R. Vishwakarma, R. Kannan, A. Sharma and B. C. Bhatt, “An Overview of Industrial Radiography Accidents in India during the period 1987-1997," Safety of Radiation Sources and Security of Radioactive Materials, Dijon, 14-18 September 1998, pp. 107-111.

[2] J. Rouzitalab “An Investigation to Dose Calculation in Gilan_Iran Industrial Radiography Accident by Using MCNP,” 18th World Conference on Nondestructive Testing, Durban, 16-20 April 2012.

[3] “Radiological Accident Is Samut Prakarn,” IAEA Accident Report, 2002.

[4] I. Turai and K. Verss, "Radiation Accidents: Occurrence, Types, Consequences, Medical Management, and Lessons to be Learned,” CEJOEM, Vol. 7, No. 1, 2001, pp. 3-14.

[5] A. K. Guskova, “Assessment of the Consequences of the Radiation Accident," Safety of Radiation Sources and Security of Radioactive Materials, Dijon, 14-18 September 1998, pp. 1-3.

[6] J. F. Briesmeister, “A General Monte Carlo N-Particle Transport Code,” LA 12625 Los Alamos National Lab, 1996.

[7] D. J. Whalen, D. E. Hollowell and J. S. Hendricks, “MCNP: Photon Benchmark Problems,” LA 12196, 1991.

[8] A. Kumar, S. P. Agarwal, U. B. Tripathi, B. K. S. Murthy and B. C. Bhatt, "Safety and Security of Radiation Materials-The Indian Scenario,” Safety of Radiation Sources and Security of Radioactive Materials, Dijon, 14-18 September 1998, pp. 51-54.

[9] Practical Radiation Safety Manual, Manual of Gamma Radiography, IAEA, 1996.

[10] A. M. El-Naggar, M. H. M. Mohammad and M. A. Gomaa, “The Radiological Accident at Meet Halfa, Qaluobiya,” Proceedings of the 4th International REAC/TS Conference on the Medical Basis for Radiation Accident Preparedness, 2001.

[11] International Commission on Radiological Protection, Bergamon Press, Oxford, 2002.

[12] Environmental Health and Safety, “Stanford California Radiation Safety Manual,” Stanford University, Stanford, 2012. 